\title{
GERENCIANDO UMA EXPERIÊNCIA INVESTIGATIVA NA PROMOÇÃO DO “VIVER SAUDÁVEL” EM UM PROJETO DE INCLUSÃO SOCIAL
}

\author{
Alacoque Lorenzini Erdmann ${ }^{1}$, Marli Terezinha Stein Backes², Dirce Stein Backes ${ }^{3}$, Magda Santos Koerich ${ }^{4}$, \\ Maria Aparecida Baggio ${ }^{5}$, Jacira Nunes Carvalho ${ }^{6}$, Betina Hörner Schlindwein Meirelles ${ }^{7}$
}

\footnotetext{
${ }^{1}$ Doutora em Filosofia da Enfermagem. Professor Titular do Departamento de Enfermagem e do Programa de Pós-Graduação em Enfermagem (PEN) da Universidade Federal de Santa Catarina (UFSC). Pesquisadora 1A do CNPq. Santa Catarina, Brasil. E-mail: alacoque@newsite.com.br

${ }^{2}$ Doutoranda do PEN/UFSC. Enfermeira da Secretaria Municipal da Saúde de Capão do Leão. Rio Grande do Sul, Brasil. E-mail: marli.backes@bol.com.br

${ }^{3}$ Doutora em Filosofia da Enfermagem. Professor do Centro Universitário Franciscano. Rio Grande do Sul, Brasil. E-mail: backesdirce@ig.com.br

${ }^{4}$ Doutoranda do PEN/UFSC. Professor Assistente do Departamento de Patologia da UFSC. Santa Catarina, Brasil. E-mail: mskoerich@ccs.ufsc.br

${ }^{5}$ Doutoranda do PEN/UFSC. Professor Substituto do Departamento de Enfermagem da UFSC. Bolsista do CNPq. Santa Catarina, Brasil. E-mail: mariabaggio@yahoo.com.br

${ }^{6}$ Doutoranda do PEN/UFSC. Professor Adjunto do Departamento de Enfermagem da Universidade Federal do Pará. Pará, Brasil. E-mail: jacira@ufpa.com.br

${ }^{7}$ Doutora em Filosofia da Enfermagem. Professor Adjunto do Departamento de Enfermagem e do PEN/UFSC. Santa Catarina, Brasil. E-mail: betinam@ccs.ufsc.br
}

\begin{abstract}
RESUMO: Relato da gerência de uma experiência investigativa pelos pesquisadores na realização de uma pesquisa-ação com oficinas educativas e de promoção da saúde junto à jovens integrantes de um projeto de inclusão social, localizado num dos morros da Grande Florianópolis-SC. Intervir na realidade a partir do significado que os próprios atores sociais atribuem ao viver saudável é uma importante estratégia no processo de (re)construção de conhecimentos e práticas em saúde/cuidado, comprometidas e engajadas na construção da cidadania. Gerenciar o processo investigativo inclui: exercitar coletivamente a construção de conhecimentos; potencializar competências investigativas na formação de pesquisadores; despertar para articulações nos espaços sociais que promovem o crescimento humano dos atores nos diferentes modos de ser e viver seu projeto de saúde. A gerência do processo investigativo em "laboratórios sociais" é desafiadora frente à realidade do "viver a vida" em busca do "viver mais saudável" em condições pouco favoráveis ao exercício pleno da cidadania. DESCRITORES: Pesquisa em enfermagem. Gestão em saúde. Cuidados de enfermagem. Promoção da saúde. Educação em saúde.
\end{abstract}

\section{MANAGING AN INVESTIGATIVE EXPERIENCE IN THE PROMOTION OF "HEALTHY LIVING" IN A SOCIAL INCLUSION PROJECT}

\begin{abstract}
This is a management report of an investigative experience by researchers carrying out an action-study by means of educational workshops and the health promotion along with young people who take part in a social inclusion project, located in one of the hills of Greater Florianópolis-SC, Brasil. Intervening in reality based on the meaning which the social actors themselves attribute to healthy living is an important strategy in the knowledge and health care practice (re)construction process, committed and engaged in the construction of citizenship. Managing the investigative process includes: to collectively exercise knowledge construction; to achieve potential investigative competences in researcher education; to give rise to articulations in social spaces which promote the human growth of the actors in the different ways of being and living their health project. Management of the investigative process in "social laboratories" is challenging faced with the reality of "living life" in search of "healthier living" in conditions which are scarcely favorable to the full exercise of citizenship. DESCRIPTORS: Nursing research. Health management. Nursing care. Health promotion. Health education.
\end{abstract}

\section{GESTIÓN DE LA EXPERIENCIA DEL INVESTIGADOR EN LA PROMOCIÓN “VIDA SANA" EN UN PROYECTO DE INCLUSIÓN SOCIAL}

RESUMEN: Informe de la experiencia de gestión realizada por investigadores en una investigación-acción con talleres educativos y de promoción de la salud con jóvenes miembros de un proyecto de inclusión social, situado en una de las colinas de la Gran Florianópolis-SC, Brasil. Intervenir en la realidad a partir del significado que los propios actores sociales atribuyen al hecho de vivir una vida saludable es una estrategia importante en el proceso de (re)construcción de conocimientos y prácticas en salud y cuidado, comprometidas y dedicadas a la construcción de la ciudadanía. Gestionar el proceso de investigación incluye: trabajar unidos para construir el conocimiento; aumentar las capacidades de investigación en la formación de los investigadores; despertar para articular espacios sociales que fomenten el crecimiento de los actores en las diferentes formas de ser y de vivir su proyecto de salud. La gestión del proceso de investigación en el "laboratorio social" se enfrenta a la difícil realidad de "vivir la vida" en la búsqueda de "una vida sana" en condiciones poco favorables para el pleno ejercicio de la ciudadanía.

DESCRIPTORES: Investigación en enfermería. Gestión en salud. Atención de enfermería. Promoción de la salud. Educación en salud. 
CONSTRUINDO PRÁTICAS DE SAÚDE/ CUIDADO E GERENCIANDO A (RE) CONSTRUÇÃO DO CONHECIMENTO

No contexto social atual, a saúde/cuidado como uma prática de educação e promoção próativa ainda está longe de se efetivar. Esta fragilidade se mostra, sobretudo, nos espaços sociais mais vulneráveis, como no caso das favelas e periferias das grandes cidades.

Em face destas situações mais vulneráveis, que retratam a possível carência de intervenções planejadas e sistematizadas e considerando ser a Enfermagem uma profissão comprometida com o cuidado integral, propõe-se pensar e refletir, enquanto pesquisadoras doGrupo de Pesquisa em Administração de Enfermagem e Saúde (GEPADES), no sentido de encontrar formas e/ou estratégias de cuidado para abarcar a complexidade das intervenções nos chamados espaços sociais mais vulneráveis. ${ }^{1}$

O racionalismo científico movido pela lógica cartesiana, ainda predominante no contexto da saúde, nos induz a pensar que viver em condições de precariedade e vulnerabilidade é viver numa condição de doença. Desconsideram-se, nessa perspectiva, os significados que os próprios atores sociais, mesmo que em condições desfavoráveis, atribuem ao seu cotidiano e, principalmente, ao seu viver saudável no cotidiano de sua realidade.

É importante e possível a busca de novas compreensões e reflexões acerca do viver saudável em tempos pós-modernos, orientados fundamentalmente, por olhares que abarcam a inserção ativa e criativa dos diferentes atores sociais em seu processo saúde e doença.

O ser saudável é uma construção a partir das condições reais em que se vive e a partir das interações que se constrói com os espaços que se compartilha. ${ }^{2}$ Compreender o ser e o viver no mundo, implica em compreender o ser a partir do significado que cada indivíduo, na sua singularidade, atribui às suas vivências, comportamentos, interações, enfim, aos diferentes movimentos de ser e relacionar-se neste mundo. ${ }^{3}$

O incentivo para um estilo de vida saudável em prol do ser saudável deve vir através de instrumentos sociais, ou seja, através de práticas sociais demandadas por redes de colaboração solidária. É preciso que todos os profissionais, empresas e organizações governamentais ou não-governamentais estejam enfronhados nesta tarefa. ${ }^{4}$

Compreender o mundo imaginário do ser família saudável no quotidiano em tempos pós- modernos, exige uma imagem de ser família saudável que elas próprias constroem ao longo de todas as interações do seu processo de viver, isto é, por meio de seus significados, crenças, valores, símbolos, situações existenciais, laços de afeto, entre outros. ${ }^{5}$ Considera-se, em síntese, que os aspectos apresentados pelas famílias como fundamentais na construção do seu ser saudável, enquanto maneira de viver, possibilita afirmar que a família do coração pode ser um caminho para ser família saudável.

Estudo acerca do "Viver saudável em tempos de AIDS: a complexidade e a interdisciplinaridade no contexto de prevenção da infecção pelo HIV", evidenciou que compreender o processo de viver humano e ser saudável é uma tarefa difícil e inatingível quando apreendida isoladamente ou de forma fragmentada. ${ }^{6}$ Para a sua concretização é preciso da cooperação e parceria dos diversos setores da sociedade, da re-ligação dos saberes disciplinares, do sentido ético e humano no viver em sociedade a fim de compreender os problemas emergentes e, sobretudo, encontrar estratégias que estimulem a promoção da saúde.

Com base nas considerações anteriores, é possível argumentar que o viver saudável é um processo singular, complexo, plural, permeado pela ordem, desordem, organização, e construído a partir dos significados que cada indivíduo ou grupo social atribui ao seu processo saúde e doença. Depende, então, dos diferentes movimentos que integram o processo de viver a saúde e a doença.

Essa compreensão de ser saudável na perspectiva de Morin, pensador da complexidade, implica em reconhecer o ser humano como um ser complexo por excelência, o qual interage por meio de comportamentos e atitudes complexas, isto é, não lineares ou previsíveis. ${ }^{7} \mathrm{O}$ autor complementa a idéia dizendo: "cada indivíduo vive e experimenta-se como sujeito singular; essa subjetividade singular, que diferencia cada um, é comum a todos" $8: 78$

Entendendo ser um dos grandes objetivos da Enfermagem a construção do conhecimento conectado com as diferentes situações do contexto de vida de cada indivíduo ou grupo social, o Programa de Pós-Graduação em Enfermagem (PEN) da Universidade Federal de Santa Catarina (UFSC), em sua estrutura teórico-filosófica, prima pela inclusão social e o desenvolvimento de competências profissionais capazes de abarcar a complexidade do processo saúde-doença em seus diferentes imaginários sociais. 
Nessa perspectiva, a dinâmica organizacional do PEN/UFSC oferece uma estrutura ágil e flexível capaz de atender as exigências da evolução do conhecimento. Dentre os propósitos, o programa permite capacitar enfermeiros e outros profissionais da saúde, para uma prática transformadora, técnica e politicamente competente, através do desenvolvimento de estudos avançados em saúde e enfermagem. Estes articulados numa perspectiva interdisciplinar, são capazes de gerar e ampliar a base filosófica, científica, política e metodológica para o desenvolvimento do conhecimento em saúde, compromissada com uma prática social transformadora, política e tecnicamente voltada para a melhoria da qualidade de vida. ${ }^{9}$

Ainda na mesma direção, o GEPADES têm como marco teórico-filosófico o processo de viver, ser saudável e adoecer com cidadania, nas condições naturais e sociais do processo de vida humana em busca do melhor viver e de melhores práticas de cuidados nos serviços de saúde.

Entendemos, a partir do exposto, que para compreender o significado do viver saudável, a partir dos diferentes imaginários sociais, é preciso investir no gerenciamento de práticas criativas e inovadoras de cuidado em enfermagem/saúde voltadas para a promoção e educação em saúde. Acreditamos que os Grupos de Pesquisa relacionados à administração e gerenciamento do cuidado de enfermagem/saúde vêm adquirindo espaços e responsabilidade crescente no sentido de criar, fomentar e propor estratégias prático-interativas capazes de levar em conta a complexidade e singularidade de cada ser humano em seu contexto real e concreto. A gerência do processo investigativo no GEPADES inclui a construção de estratégias no processo de re-construção de conhecimentos que viabilizem mudanças ou transformações sociais.

Foi pensando nestas e outras questões, que alguns integrantes do GEPADES iniciaram, no ano de 2007, um Projeto de Pesquisa no intuito de compreender, inicialmente, o significado do "viver saudável" para os jovens que integram o Centro Cultural Escrava Anastásia (CCEA) e, a partir dos significados evidenciados, instaurarem um processo de intervenção com estratégias do processo de investigação-ação centradas em oficinas interativas e educativas capazes de promover a saúde e a cidadania. Também teve o propósito de subsidiar estratégias para posteriores trabalhos desta natureza, a serem realizados com grupos vulneráveis.
Propomos-nos, neste artigo, relatar a gerência de uma experiência investigativa do ponto de vista dos pesquisadores mediante a realização de uma pesquisa-ação com jovens integrantes de um projeto de inclusão social, localizado em um dos morros da Grande Florianópolis-SC, por meio de oficinas educativas e de promoção da saúde. Entendemos ser esta uma proposta relevante para compreender os desafios que se apresentam àqueles que se propõem a um trabalho de inserção e intervenção social como uma experiência investigativa, principalmente, nos espaços considerados de maior vulnerabilidade social.

\section{RECONHECENDO O LOCAL E EXPLICI- TANDO A METODOLOGIA DA PROPOS- TA DE TRABALHO}

O CCEA, projeto de inclusão social, foi fundado em sete de junho de 1994, na capela Nossa Senhora do Monte Serrat da Grande Florianópolis e o seu registro oficial, em Cartório, no dia 25 de maio de 1998. Nasceu, a partir do trabalho de um grupo da comunidade, que tinha como objetivo a educação e que reunia representantes de diferentes entidades e instituições, dentre elas: Escola Básica Lucia Livramento Mayvorne, Creche Casulo LBA, Creche Monte Serrat, Grupo Pinheiro e Escola de Datilografia.*

Os objetivos destas entidades centravamse, inicialmente, no fortalecimento das relações interpessoais, buscando estimular, intensificar e aperfeiçoar a reflexão e a participação na vida comunitária. O Centro Cultural foi projetado com a finalidade de abrigar projetos e atividades educativas para os moradores do Morro. A partir desta iniciativa desencadearam-se outros projetos articulados pelo CCEA como: Projeto Travessia, Movimento dos Trabalhadores oriundos dos Quilombos e o Fórum do Maciço, todos tendo como foco a articulação de forças sociais e a constituição de redes. Esse processo possibilitou a existência do Aroeira - Consórcio Social da Juventude, no qual o projeto de pesquisa em questão está articulado e engajado mais efetivamente.

Surgido a partir do convênio entre o Governo Federal - Ministério do Trabalho - e o CCEA, o Aroeira assume o compromisso de articular sujeitos coletivos, atuantes nas comunidades de periferia da Grande Florianópolis, para o desenvolvimento de processos educativos que visem possibilitar a jovens entre 16 e 24 anos, em

* Groh V. Centro Cultural Escrava Anastácia. Documento Base; 2006.

Texto Contexto Enferm, Florianópolis, 2009 Abr-Jun; 18(2): 369-77. 
situação de vulnerabilidade social, o aumento da auto-estima e da compreensão da realidade sóciocultural, o compromisso comunitário e cidadão e a inserção no mundo do trabalho, buscando o empoderamento e a autonomia desses sujeitos individuais e coletivos. ${ }^{* *}$

Tendo reconhecido as atividades do CCEA, que apresentava uma carência de cuidados de saúde/enfermagem, alguns integrantes do GEPADES se propuseram, por meio de um projeto de uma pesquisa-ação, a desenvolver uma série de atividades, a partir do ano de 2007, nesse espaço.

A proposta de pesquisa compreendeu duas etapas sistematizadas e interligadas. $\mathrm{Na}$ primeira etapa nos propomos, enquanto pesquisadoras, a compreender o significado do viver saudável na perspectiva dos jovens do CCEA por meio do método da Grounded Theory ${ }^{10-11} \mathrm{e}$, na segunda, realizar uma experiência investigativa de um processo de intervenção com o apoio da pesquisa-ação. ${ }^{12}$

O presente artigo focará, no entanto, apenas à segunda etapa, na qual as pesquisadoras tiveram uma inserção no projeto de inclusão social, por meio da pesquisa-ação, mais especificamente por meio de oficinas educativas e de promoção da saúde, com três grupos de jovens existentes (Grupo da Gastronomia, Grupo da Estética e Grupo da Comunidade Nova Descoberta). Nas oficinas, num total de 15 encontros, foram trabalhados os seguintes temas, sugeridos pelos próprios jovens: o significado do viver saudável, o conhecimento do corpo humano, as DST, sexualidade e os métodos anticoncepcionais. Além destes temas, foram sugeridos outros que serão trabalhados posteriormente, tais como: leptospirose, natureza, meio ambiente, reciclagem do lixo, promoção da saúde, desnutrição, desidratação, música e esportes.

Os relatos foram registrados por seis pesquisadoras, autoras do estudo, após cada um dos 15 encontros com os jovens, e foram discutidos, analisados e descritos por todas as autoras deste artigo.

Trata-se, portanto, de um relato de experiência das pesquisadoras e autoras sobre o processo gerencial vivido nesta pesquisa-ação com as oficinas educativas e de promoção da saúde junto com jovens integrantes de um projeto de inclusão social, localizado em um dos morros da Grande Florianópolis-SC.

São recortes de falas dos pesquisadores que dão voz ao processo de reflexão e discussão pelos mesmos nos encontros do grupo de pesquisa. As pesquisadoras foram denominadas com a letra " $p$ " e um número na identificação das falas relatadas em seis depoimentos.

O projeto de pesquisa, objeto deste relato, seguiu todas as recomendações da Resolução N 196/96 do Ministério da Saúde, ${ }^{13}$ sendo submetido e aprovado pelo Comitê de Ética em Pesquisa da UFSC, na reunião de 17 de dezembro de 2007, sob o No $350 / 07$.

\section{A GERÊNCIA DE UMA PESQUISA-AÇÃO NA CONSTRUÇÃO DO VIVER SAUDÁ- VEL: DANDO VOZ AOS PESQUISADO- RES, ATORES DESSE PROCESSO.}

Salienta-se que anteriormente ao projeto em curso, o desenvolvimento de ações de saúde/ cuidado aos jovens do CCEA estava restrito à execução de ações diretamente dirigidas aos problemas, mais especificamente quando os jovens eram encaminhados ou buscavam a Unidade Local de Saúde e aí eram avaliados e atendidos conforme suas necessidades. A resolução do problema, naquele contexto, se reduzia ao aspecto individual, prestado de forma fragmentada e sem ênfase na promoção e educação em saúde.

Esta constatação, previamente observada, nos fez pensar e refletir na necessidade de promover a gerência/gestão do viver saudável na perspectiva dos jovens, isto é, a partir da compreensão da ação social como um sistema aberto à troca de informações e interações. Mais especificamente, a partir da superação das dicotomias clássicas por meio da promoção de interdependências e vínculos efetivos entre os serviços de saúde, universidades e atores sociais. ${ }^{14}$

Frente às evidências de que a realidade em questão deixava a desejar em termos de promoção e educação em saúde, buscamos instaurar um processo de intervenção que levasse em conta aspectos do viver saudável, a partir de medidas práticas participativas e construtivistas, do ponto de vista dos pesquisadores como também dos jovens.

A partir do que vivenciamos nas oficinas educativas com os jovens, ficou a certeza do quanto é desafiador ser professora-pesquisadora. [...] chamou a atenção o fato da necessidade sentida pelos jovens de realmente quererem tomar conhecimento acerca do seu próprio corpo. Com relação aos jovens percebi que precisamos ser pacientes e dar tempo para que eles se sintam à

** Groh V. Centro Cultural Escrava Anastácia. Documento Base; 2006. 
vontade e livres para expressarem os seus sentimentos. Somente a presença do pesquisador não é suficiente. É preciso estar com eles para poder compreender o seu processo de viver e, então, entender suas expectativas, seus significados e dúvidas (p1).

Do relato acima, destaca-se a expressão é preciso estar com ele. É fundamental e emergente que se desenvolvam espaços de convivência e partilhas de vida pelo diálogo aberto com a realidade concreta dos atores sociais, não somente para capturar informações "dados de pesquisa", mas para "estar junto", isto é, compreender as singularidades, complexidades e pluralidades subjacentes no cotidiano existencial.

Sem muito pensar, os questionamentos nos reportaram a afirmativa de Morin que diz: "Hoje, a presença da dialógica, da ordem e desordem mostra que o conhecimento deve tentar negociar com a incerteza. Isso significa ao mesmo tempo em que o objetivo do conhecimento não é descobrir o segredo do mundo ou a equação-chave, mas dialogar com o mundo". 8:205

Durante 17 anos trabalhei como enfermeira em hospital geral. Nessa época considerava as atividades nas Unidades Básicas de Saúde como de menor importância e acreditava que os profissionais de lá sabiam menos que os dos hospitais. Estou, e sempre estive profissionalmente envolvida com a doença e muito pouco com prevenção ou promoção da saúde. Ao inserir-me nesse projeto, pretendia não me envolver... Nosso interesse maior era a pesquisa, compreender como aqueles jovens percebiam e que significados atribuíam ao viver saudável. Questionávamos como seria possível ser saudável nas condições sociais problemáticas em que os jovens estavam envolvidos. E assim, subimos o morro! Para mim, poucas atividades foram tão gratificantes como esta, tanto nos aspectos profissionais e de aprendizagem em pesquisa, como também pessoalmente... percebi o quanto esperavam de nós. Demonstravam de maneira enfática o quanto contavam conosco para orientar as questões de saúde. Essa expectativa em relação a nós me deixou apreensiva. Cada um dos três grupos apresentava características diferentes e todos eram desafiadores. Estava diante do desconhecido! As histórias de vida daqueles jovens me sensibilizaram para a importância de aproximar a academia da comunidade. Como gastamos nossa energia em produção de conhecimentos aos quais essa parcela da população não tem acesso! Percebo esse projeto como uma aula prática sobre produção de conhecimento em Enfermagem e saúde (p2).

Este segundo relato demonstra, de um lado, o estranhamento diante do novo e do diferente e, de outro, a possibilidade de continuamente fazermos novas e construtivas descobertas, capazes de provocar a "zona de conforto". A frase - As histórias de vida daqueles jovens me sensibilizaram para a importância de aproximar a academia da comunidade, evidencia que a transformação pessoal e social começa ou deve começar pela academia. É preciso, gradativamente, transcender o tradicional e hegemônico "espaço sala de aula" para o "espaço laboratório social", o qual possibilita o encontro das intersubjetividades e permite acolher e integrar o diferente, o incerto e o aleatório ao processo de construção do conhecimento.

É inegável que experiências desta natureza, longe dos bancos acadêmicos tradicionais, acabam por provocar um confronto pessoal e profissional capazes de instaurar um novo raciocínio e um novo modo de compreender os fenômenos sociais, muitas vezes, confundidos e não compreendidos aos olhos cientificizados, como bem esclarece a perspectiva do pensamento complexo. ${ }^{7}$

[...] apesar de termos sido bem recebidas pelos integrantes do primeiro encontro tive a impressão muito forte de que manifestavam um sentimento de "medo", ou seja, algo como se o trabalho ou a presença de pessoas estranhas ao ambiente (nesse caso dos pesquisadores) pudesse comprometer alguma "coisa". O entra e sai de alguns integrantes, isto é, saídas estratégicas, pareceu-nos bastante estranho. Algo peculiar aconteceu no final da primeira oficina, visto que o coordenador do grupo ficou muito preocupado com o recado recebido por alguém de fora que o tirou do grupo e the falou: "fulano, vem cá!" (parecia apreensivo) e, logo lhe disse, ainda: "é urgente!". Assim como estas expressões, várias outras se fizeram presentes ao longo das diferentes oficinas. Por vezes me sentia como estranha, por vezes me sentia uma verdadeira heroina... (p3).

A expressão manifestavam um sentimento de medo, evidencia, em síntese, o "estranhamento" entre academia/pesquisadores e atores sociais/jovens em situação de vulnerabilidade. Nessa direção questionamo-nos: de que forma a saúde ou os profissionais da saúde podem ou devem interferir nesta "ordem social já estabelecida"? Como provocar uma nova organização ou ordem social nestes espaços, considerados como desagregadores e perigosos?

Pelo olhar da complexidade nada está perdido, mas tudo é possível e passível de uma nova organização. ${ }^{7}$ Desse modo, compreender o significado desta organização específica dos jovens, significa acolher o processo de ordem-desordemorganização que caminham paralelamente num esforço pela sobrevivência humana. Significa 
compreender e acolher o estranhamento, como algo inerente à existência humana e como possibilidade de uma nova (re)organização, mesmo que inicialmente incompreendido aos olhos da simplificação.

As primeiras oficinas foram, além de educativas, também de estranhamento e conhecimento uns dos outros. Houve o estranhamento por parte dos integrantes do grupo e da própria comunidade, que para sentiremse seguros no seu contexto, precisaram conhecer quem eram as pessoas estranhas, de onde vinham e quais as intenções/interesses para com o grupo e comunidade. [...] Conviver por algumas horas com esses jovens, ao mesmo tempo em que impressiona, provoca e assusta, é um momento de aprendizagem, de solidariedade, de cuidado e admiração pelas diferentes formas de expressarem os talentos artísticos, como também os significados que atribuem ao cotidiano em que vivem. Percebo que a educação e promoção da saúde decorrem da interação e da relação entre as pesquisadoras e os jovens, estas, permeadas pelo diálogo e pelo respeito à diversidade ( $\mathrm{p} 4)$.

A solidariedade, o cuidado interativo, a admiração pelo novo e diferente e a valorização do outro como ser uno e complexo, nascem do encontro intersubjetivo e do contato com a realidade concreta dos sujeitos, como já fora dito anteriormente.

O processo de aprendizagem evidenciado no relato acima mostra que precisamos, enquanto pesquisadores, conhecer profundamente a cultura em que os indivíduos sociais ou grupos coletivos estão inseridos. Em outras palavras, precisamos compreender como as questões estruturantes dessa cultura podem nos ajudar a entender os modos particulares nos quais os indivíduos ou um grupo social vive e dá sentido à sua condição de vida. ${ }^{15}$

Muito mais que construir novos conhecimentos, a experiência do morro foi para mim um processo de desconstrução de muitas verdades acumuladas ao longo dos anos acadêmicos. [...] Pude perceber o quanto é difícil lidar e gerenciar os conflitos e confrontações pessoais e encontrar alternativas e estratégias de inclusão social principalmente nas realidades sociais mais vulneráveis, quando seria fácil, nesse momento, atribuir toda a responsabilidade aos representantes de governo. Muitas vezes, senti o peso da nossa responsabilidade social enquanto enfermeiras, pesquisadoras, ou seja, profissionais formadas e preparadas para intervir com conhecimento e competência nas diferentes demandas sociais. Outras vezes, sentia vontade de gritar e julgar as autoridades que pouco se importam com estas realidades. [...] Precisamos articular, integrar e potencializar as diferentes formas de conhecimento para compreendermos o real significado do processo de viver saudável nos diferentes imaginários e espaços sociais (p5).

Este relato de p5, principalmente na expressão o peso da nossa responsabilidade social enquanto enfermeiras, pesquisadoras, provoca a uma série de indagações, quais sejam: Qual a nossa responsabilidade social enquanto enfermeiros e pesquisadores, face às crescentes injustiças e desigualdades sociais? Qual a nossa parcela de responsabilidade face aos chamados "excluídos sociais"? O que estamos fazendo concretamente enquanto cidadãos no sentido de promover a inclusão social?

Falar de sentimentos, significados e percepções a partir de uma realidade vivenciada, longe da academia e dos saberes formalmente instituídos, provocou, a priori, sentimentos de dúvida, medo, insegurança e incertezas os quais, gradativamente, foram suplantados por uma sensação de bem-estar e satisfação profissional, como mostram os recortes das falas acima. Se não é possível salvar o mundo, que façamos pelo menos a nossa parte.

A educação dos jovens não é tarefa fácil e pudemos evidenciar isto, pois nem sempre as nossas atividades eram priorizadas. O contato que tivemos foi com a participação de adolescentes/jovens em grupos como o da Gastronomia ou com uma mãe que trazia seu filho para as oficinas no Grupo da Estética. Mas, também ficou evidente que muitos dos conhecimentos, principalmente as crenças e preconceitos a respeito de temas como sexualidade e doenças sexualmente transmissíveis, são repassados através da família, de gerações a gerações. Era comum a experiência familiar ilustrar as discussões durante as oficinas, muitas vezes carregadas de mitos e significados ( $\mathrm{p} 6)$.

Mesmo que em muitos momentos as atividades educativas não tenham sido priorizadas pelos jovens, pode-se perceber a vontade de vencer, de recomeçar e a esperança de novamente poderem voltar a sonhar, sonho este que, para muitos jovens que viviam à margem da sociedade e/ou numa condição de fuga, drogas e outros, não passava de uma utopia. Os jovens demonstraram, por meio de suas atitudes e expressões, que sonham com algo novo e diferente, para o qual nós profissionais da saúde ainda não despertamos.

Rostos sofridos, corpos machucados, corações feridos são algumas das expressões que foram visibilizadas sem muito esforço de pensamento. Compreender os sentimentos que cada jovem, cada integrante do Morro, resguardava para si, no entanto, já foi uma tarefa por si só 
desafiadora e indutora de novos conhecimentos e possibilidades educativas.

Em muitos momentos chegamos à conclusão de que não compreendíamos nem mesmo a nossa realidade cientificizada pelos valores e conhecimentos hegemônicos de uma sociedade que se diz "perfeita" e "segura" de todas as verdades. Assim, compreender o jovem "ex-traficante" como cidadão, com potencial para transformar a sua realidade pessoal e o contexto social como um todo, exigiu, inicialmente, rever posturas e atitudes, confrontar valores, para compreender e aceitar o diferente.

O processo de intervenção por meio das oficinas demonstrou que a enfermagem pode ter uma atuação relevante nesta área específica, através do estabelecimento de vínculos seguros, construídos a partir de uma interação de confiança, de caráter educativo e de promoção da saúde, fato este já demonstrado por estudos anteriormente realizados. ${ }^{16}$

Podemos constatar a importância dos aspectos culturais e, principalmente do nível de escolaridade e da Escola, para os sujeitos frente aos programas de prevenção e as formas de reagir às agressões do meio, como também a capacidade de mensurar o impacto destas questões em suas vidas. Logicamente, não houve um interesse em conhecer este aspecto especificamente, mas observamos que os relatos mais elaborados ou parte dos conhecimentos com base científica, que os adolescentes detêm sobre as questões discutidas, foram repassados nas escolas, geralmente nas aulas de biologia.

Acreditamos que todos estes aspectos têm relevância, pois quando falamos em "viver saudável", não podemos deixar de dar um espectro mais amplo a este fato. Implica na adoção do pensamento de que, para que as ações de promoção da saúde e melhor qualidade de vida sejam mais efetivas, temos que envolver vários aspectos do viver relacionados à educação, cultura, condições socioeconômicas, aspectos psicológicos, biológicos e comportamentais, além da saúde, constituindose numa rede de inter-relações. Esta é uma discussão que desenvolvemos em alguns momentos, até porque as diferenças de distribuição de renda e sociais eram citadas em muitos momentos.

Por fim, nosso grande desafio consiste em aproximar e integrar o conhecimento científico ao saber popular; em sentir e significar o viver saudável a partir da compreensão dos atores sociais; em integrar o local ao global ${ }^{1}$ o que não significa que devemos ou podemos transformar tudo. O nosso esforço, enquanto pesquisadoras, deve ser sempre o de criar estratégias viáveis, ou seja, ir além da quantidade de informações que já estão disponíveis. Nessa perspectiva propomos estratégias de gerenciamento, tais como:

- intervenção real e concreta nas realidades socialmente vulneráveis;

- aproximação do saber acadêmico ao saber popular;

- projetos de pesquisa a partir dos reais problemas sociais;

- processo investigativo mais aberto às diferentes possibilidades de apreender e interpretar mais coletivamente a realidade social;

- pesquisas que, além de investigativas, tenham também uma intervenção social;

- propostas criativas e interdisciplinares de intervenção social;

- exercício do aprender gerenciando processos que potencializam competências investigativas na formação de recursos humanos em pesquisa;

- "laboratórios sociais" para a compreensão do mundo real do "viver a vida" em busca do "viver mais saudável".

O exercício do processo investigativo é a oportunidade de aprender gerenciando um trabalho coletivo de construção de conhecimentos cujas competências são potencializadas nos grupos de pesquisa, espaços de formação de recursos humanos em pesquisa nos diferentes níveis. Estas competências político-gerenciais, de atitudes e visão de compromisso social, centram-se no exercício de articulações construtivas e dialógicas, rumo ao alcance de metas e produtos importantes para o desempenho do grupo.

A prática da construção e viabilização de projetos de pesquisa nos grupo de pesquisa se constitui num solo fértil de experiências potencializadoras de formação de pesquisadores e de consolidação de conhecimentos em linhas de pesquisa ou temáticas relevantes para o avanço da profissão como ciência comprometida com a busca de melhor saúde dos cidadãos ou grupos sociais.

Gerenciar o processo investigativo requer que se implemente o processo gerencial no projetar/conceber, implementar e analisar ações e estratégias que resultem na construção de novos conhecimentos ou saberes e em práticas alicerçadas por estes novos conhecimentos ou saberes rumo a mudanças e/ou transformação social. 


\section{CONSIDERAÇÕES FINAIS}

Para construir o viver mais saudável é preciso conhecer, se interar e se apropriar dos significados vivenciados no quotidiano imaginário de cada indivíduo e grupo social. Incrementar práticas diferenciadas em saúde/cuidado, implica em construir e/ou projetar práticas importantes do ponto de vista do sujeito, substantivas cientificamente e viáveis economicamente.

O relato da gerência de uma experiência investigativa do ponto de vista das pesquisadoras, mediante a realização de uma pesquisa-ação com jovens integrantes de um projeto de inclusão social, localizado em um dos morros da Grande Florianópolis, por meio de oficinas educativas e de promoção da saúde, aponta para estratégias importantes tanto para o processo investigativo na sua concepção e viabilização, como para os pesquisadores como seres políticos, em suas atitudes e visão sobre seu compromisso social.

De outro modo, a intervenção na realidade a partir do significado que os próprios atores sociais atribuem ao viver saudável, é uma importante estratégia gerencial no processo de (re)construção do conhecimento acadêmico e a possibilidade de contribuir de forma ativa e responsável na construção de práticas em saúde/cuidado, comprometidas e engajadas na construção da cidadania.

Destacam-se ainda como pontos significativos deste relato sobre a gerência do processo investigativo: a importância do experienciar o exercício de construção de conhecimentos coletivamente; o aprender gerenciando o processo que potencializa competências investigativas na formação de recursos humanos em pesquisa em diversos níveis; e, o despertar para articulações nos espaços sociais que promovem o crescimento humano dos atores por relações múltiplas e diversas, interagindo e respeitando os diferentes modos de ser e de viver o projeto de saúde de cada cidadão.

A gerência do processo investigativo em "laboratórios sociais" é desafiadora na medida em que a academia se aproxima do mundo real do "viver a vida" em busca do "viver mais saudável" em condições pouco ou nada favoráveis à concretude do exercício pleno da cidadania na gestão do "viver saudável".

\section{REFERENNCIAS}

1. Porto MFS. Uma ecologia Política dos Riscos: princípios para integrarmos o local e o global na promoção da saúde e da justiça ambiental. Rio de Janeiro (RJ): FIOCRUZ; 2007.

2. Penna CM. Ser saudável no quotidiano da favela. Pelotas (RS): Ed. Universitária/UFPEL; 1997.

3. Silva AL, Borenstein MS. Ser e viver saudável no mundo: buscando novos caminhos no cuidar pesquisando com o ser-doente. Texto Contexto Enferm. 1992 Jul-Dez; 1(2):56-69.

4. Erdmann AL. A organização e o ser saudável. Texto Contexto Enferm. 1992 Jul-Dez; 1(2):114-9.

5. Niestcke RG. Uma viagem pelo mundo imaginal de ser família saudável no quotidiano em tempos pós-modernos: a descoberta dos laços de afeto como caminho [tese]. Florianópolis (SC): Universidade Federal de Santa Catarina. Programa de PósGraduação em Enfermagem; 1999.

6. Meirelles BHS. Viver saudável em tempos de AIDS: a complexidade e a interdisciplinaridade no contexto de prevenção da infecção pelo HIV [tese]. Florianópolis (SC): Universidade Federal de Santa Catarina. Programa de Pós-Graduação em Enfermagem; 2003.

7. Morin E. Ciência com Consciência. $7^{\mathrm{a}}$ ed. Rio de Janeiro (SC): Bertrand Brasil; 2003.

8. Morin E. O método 5: a humanidade da humanidade. Porto Alegre (RS): Sulina; 2002.

9. Programa de pós-graduação de enfermagem UFSC [página na Internet]. Estrutura do curso de Doutorado. Florianópolis (SC): Universidade Federal de Santa Catarina. [acesso 2007 Nov 08]. Disponível em: http://www.nfr.ufsc.br/pen/ estrDou.htm/

10. Strauss A, Corbin J. Basics of qualitative research: grounded theory procedures and techniques. Califórnia (US): Sage Publications; 1990.

11. Strauss A, Corbin J. Bases de la investigación cualitativa. Técnicas y procedimientos para desarrollar la teoría fundamentada. Medelin (CO): Ed. Universidad de Antioquia; 2002.

12. Thiollent M. Metodologia da pesquisa-ação. $4^{\mathrm{a}} \mathrm{ed}$. São Paulo (SP): Editora Cortez; 2000.

13. Ministério da Saúde (BR), Conselho Nacional de Ética em Pesquisa. Resolução No 196 de 10 de outubro de 1996: diretrizes e normas técnicas regulamentadoras de pesquisa envolvendo seres humanos. Brasília (DF): MS; 1996.

14. Martins PH. As redes sociais, o sistema da dádiva e o paradoxo sociológico. In: Martins PH, Fontes B. organizadores. Redes sociais e saúde: novas possibilidades teóricas. Recife (PE): Ed. Universitária da UFPE; 2004. p.21-48.

15. Reibnitz KS, Prado ML. Formação do profissional crítico-criativo: a investigação como atitude de (re) conhecimento do mundo. Texto Contexto Enferm. 2003 Jan-Mar; 12(1):26-33. 
16. Ferreira CLL, Cartana MHF. A enfermagem e o cuidado de crianças vítimas de abuso e exploração sexual. Texto Contexto Enferm. 2003 Abr-Jun; 12(2):230-7.

E-mail: marli.backes@bol.com.br 